\title{
Eugonadal male patients with adrenal incidentalomas and subclinical hypercortisolism have increased rate of vertebral fractures
}

\author{
lacopo Chiodini*, Raffaella Vitił, Francesca Coletti†, Giuseppe Guglielmi§, Claudia Battistał, \\ Federica Ermeticiף, Valentina Morelli*' $\uparrow$, Antonio Salcuni*, Vincenzo Carnevale**, Filomena Urbano§, \\ Silvana Muscarella§, Bruno Ambrosiף, Maura Arosio*' $†$, Paolo Beck-Peccoz* and Alfredo Scillitani‡ \\ ${ }^{\star}$ Department of Medical Sciences, University of Milan, Endocrinology and Diabetology Unit, Fondazione Policlinico, \\ Mangiagalli e Regina Elena, IRCCS, Milan, Italy, †Unit of Endocrinology 'San Giuseppe-Milanocuore' Hospital, Fatebenefratelli \\ Research Association (A.Fa.R), Milan, Italy, $\ddagger$ Unit of Endocrinology, $\$$ Radiology and ${ }^{\star \star}$ Internal Medicine 'Casa Sollievo della \\ Sofferenza', IRCCS, San Giovanni Rotondo, Foggia, Italy, 9 Unit of Endocrinology, Department of Medical and Surgical Sciences, \\ University of Milan, IRCCS Policlinico San Donato Institute, San Donato Milanese, Milan, Italy
}

\section{Summary}

Objective Subclinical hypercortisolism $(\mathrm{SH})$ is suggested to exert a deleterious effect on bone. This effect and the role of gonadal status in male subjects are not fully elucidated. We evaluated bone mineral density (BMD) and prevalence of vertebral fractures in eugonadal male subjects with adrenal incidentalomas $(\mathrm{AI})$ and without $\mathrm{SH}$.

Design This 12-month observational multicentre study was performed between January and December 2006 on inpatient basis in three referral Italian centres.

Patients Eighty-eight consecutive eugonadal male patients with AI and 90 matched control subjects were studied.

Measurements All subjects underwent the determination of BMD by dual-energy X-ray absorptiometry at lumbar spine (LS) and femoral neck (FN), and spinal radiograph. In AI patients $\mathrm{SH}$ was diagnosed in the presence of two of the following: urinary free cortisol $>193 \cdot 1 \mathrm{nmol} / \mathrm{l}$, cortisol after $1 \mathrm{mg}$ dexamethasone suppression test $>82 \cdot 8 \mathrm{nmol} / \mathrm{l}$, ACTH levels $<2 \cdot 2 \mathrm{pmol} / \mathrm{l}$.

Results As compared to patients without $\mathrm{SH}(\mathrm{SH}-, n=66)$ and controls, patients with $\mathrm{SH}(\mathrm{SH}+, n=22)$ had lower BMD at LS ( $Z$-score: SH+, $-1 \cdot 04 \pm 1 \cdot 84 ; \mathrm{SH}-, 0 \cdot 19 \pm 1 \cdot 34$, Controls $0 \cdot 20 \pm 1 \cdot 28$, $P=0.001$ and $\mathrm{FN}$ ( $Z$-score: $\mathrm{SH}+,-0.63 \pm 1.01$; SH-, $0.01 \pm 1.01$, Controls $0 \cdot 26 \pm 1 \cdot 06, P=0.002)$ and higher prevalence of fractures (SH+, $72 \cdot 7 \%$; $\mathrm{SH}-, 21 \cdot 2 \%$, Controls $20 \cdot 0 \%, P=0 \cdot 0001)$. Multivariable analyses showed that $\mathrm{SH}$ was associated to BMD at $\mathrm{LS}(\beta=-0 \cdot 378$, $P=0 \cdot 0001)$ and vertebral fractures $(\mathrm{OR}=7 \cdot 81,95 \% \mathrm{CI} 1 \cdot 96-31 \cdot 17$, $P=0 \cdot 004)$.

Correspondence: Iacopo Chiodini, Unit of Endocrinology and Diabetology Unit, Department of Medical Sciences, Pad. Granelli, Fondazione Policlinico, Mangiagalli e Regina Elena, IRCCS, Milan, Italy. Tel.: +39 25503 3355; Fax: +3925032 0605; E-mail: iacopo.chiodini@email.it
Conclusion In eugonadal male patients with $\mathrm{AI}, \mathrm{SH}$ is associated with low BMD and high prevalence of vertebral fractures.

(Received 28 December 2007; returned for revision 18 January 2008; finally revised 13 March 2008; accepted 20 May 2008)

\section{Introduction}

Incidentally discovered adrenal masses (adrenal incidentalomas, AI) are diagnosed with increasing frequency in patients evaluated by imaging techniques for unrelated disorders. The great majority of these lesions are benign adrenocortical adenomas. ${ }^{1}$ Although by definition, AI are not associated with clinical signs of hormonal hypersecretion, some AI patients may show a subtle degree of cortisol excess, commonly defined as 'subclinical hypercortisolism' $(\mathrm{SH}){ }^{2,3}$ This condition has been suggested to be associated to several complications, including bone loss, which is a typical feature, even not specific, of overt cortisol excess. ${ }^{4}$

Indeed, most of the previous studies, ${ }^{5-12}$ even not all, ${ }^{13-15}$ strongly suggested a possible negative effect of $\mathrm{SH}$ on bone. Nevertheless, data about the most common complication of bone loss, such as vertebral fractures, are scarce. The only study focused on this topic found a higher proportion of vertebral fractures in AI female patients with $\mathrm{SH},{ }^{12}$ while no study has been performed so far on vertebral fractures in male patients with and without SH. This point seems of utmost importance as the presence of vertebral fractures is a strong predictor of future fractures. ${ }^{16}$ Thus, the finding of reduction of bone mass and/or the presence of vertebral fractures may help to address the treatment of choice in $\mathrm{AI}$ patients with $\mathrm{SH}$.

In the present study we evaluated the spinal and femoral bone mineral density (BMD) and the prevalence of vertebral fractures in 88 eugonadal male AI patient with and without SH. 


\section{Subjects and methods}

\section{Subjects}

Eighty-eight consecutive male patients with AI were enrolled from January to December 2006 in three referral Italian centres 'Casa Sollievo della Sofferenza' Scientific Institute in San Giovanni Rotondo, 'San Giuseppe-Milanocuore-AFaR' Hospital and 'Fondazione Ospedale Maggiore Policlinico, Mangiagalli e Regina Elena’ Scientific Institute in Milan.

We included only male subjects in order to avoid the possible confounding gender-related effects on the skeleton. ${ }^{17}$ Diagnosis of AI was based on the detection of a unilateral adrenal mass by noninvasive imaging methods of the abdomen, performed for unrelated disease. The exclusion criteria were: (i) past or current history of hypogonadism (testosterone levels $<9.4 \mathrm{nmol} / \mathrm{l}$ ) ${ }^{18}$ and of other diseases known to affect bone metabolism (i.e. primary or secondary hyperparathyroidism, thyrotoxicosis, bowel diseases, chronic renal failure, chronic hepatic disease, depression, alcoholism, eating disorders, rheumatologic or haematological diseases); (ii) administration of drugs influencing bone, cortisol and dexamethasone (Dex) metabolism or cortisol secretion; (iii) signs or symptoms specific of cortisol excess (moon facies, striae rubrae, skin atrophy, buffalo hump).

On the basis of the presence or absence of $\mathrm{SH}$, patients were divided into Group SH+ $(n=22)$ and SH- $(n=66)$, respectively. The diagnosis of $\mathrm{SH}$ was based on the presence of two out of the following three alterations of hypothalamic-pituitary-adrenal (HPA) axis secretion: (i) urinary free cortisol (UFC) levels $>193 \cdot 1 \mathrm{nmol} / \mathrm{l}$, that is, the cut off of both our own and international ${ }^{19}$ normal reference values; (ii) morning ACTH levels $<2 \cdot 2 \mathrm{pmol} / \mathrm{l}$; (iii) serum cortisol levels at 09.00 a.m. after 1-mg Dex suppression test (cortisol after Dex) $>82 \cdot 8 \mathrm{nmol} / \mathrm{l}$.

No subject had evidence of metastatic diseases. At computed tomography (CT) all adrenal masses were homogeneous, hypodense and well shaped, features consistent with the diagnosis of adrenocortical adenomas. No CT scan was performed for malignancy staging. Patients from group $\mathrm{SH}+$ showed a higher mean diameter of adrenal masses than those from group $\mathrm{SH}-$, even if without reaching statistical significance (mean $\pm \mathrm{SD}, 3 \cdot 0 \pm 1 \cdot 1$ vs. $2 \cdot 5 \pm 1 \cdot 1 \mathrm{~cm}, P=0 \cdot 066$; range $1 \cdot 0-5 \cdot 0$ and $1 \cdot 0-6 \cdot 4 \mathrm{~cm}$, respectively). Five patients whose AI was higher than $4.0 \mathrm{~cm}$ had previously refused surgery and were sent to our Departments to assess the possible presence of hormonal hypersecretion. In all patients the diagnosis of pheochromocytoma and aldosteronoma was excluded by appropriate hormonal (24-h urinary cathecolamines and plasma renin activity and aldosterone after $3 \mathrm{~h}$ of upright position) and clinical determinations.

Because the inpatient status can increase cortisol secretion, during the same time a control group of 90 male inpatients matched for age and BMI was recruited. These subjects were consecutively enrolled on the basis of the above-mentioned inclusion criteria from our outpatients clinics where they referred for unrelated diseases (simple goiter with normal thyroid function).

In all subjects data about the presence of type 2 diabetes and/or hypertension were obtained. Patients with confirmed fasting plasma glucose level $\geq 7.0 \mathrm{mmol} / \mathrm{l}$ ) or with casual or during an oral glucose tolerance test plasma glucose concentration $\geq 11 \cdot 1 \mathrm{mmol} / \mathrm{l}$ were defined as diabetics. Subjects with systolic blood pressure $\geq 130 \mathrm{mmHg}$ and/or diastolic blood pressure $\geq 85 \mathrm{mmHg}$ and/or on antihypertensive treatment were defined as hypertensive.

All subjects gave their witnessed informed consent before entering the study, which was approved by local ethical committees and in accordance with Helsinki Declaration II.

\section{Methods}

All samples were taken from all patients at the same time of day. Serum and urinary samples were collected and stored at $-20{ }^{\circ} \mathrm{C}$ until assayed. In all patients serum ACTH levels (mean of three determinations at 20 -min intervals) were measured by IRMA (BRAHMS Diagnostica GmbH, Berlin, Germany), serum cortisol and UFC levels (after dichloromethane extraction) were determined immunofluorimetrically by TDX-FLX Abbott, GmbH, Diagnostika kits (Wiesbaden-Delkenheim, Germany) and dehydroepiandrosterone (DHEA-S) and testosterone levels by chemiluminescence (Immulite, Diagnostic Products Corporation, Los Angeles, CA). The intra- and interassay coefficients of variation for all assays were $<5 \%$ and $10 \%$, respectively.

In all patients spinal L1-L4 BMD was measured by dual-energy X-ray absorptiometry (DXA) (Hologic Discovery, Watham MA) at spine (DXA L1-L4, in vivo precision $1.0 \%$ ) and total and femoral neck (FN) (in vivo precision $1 \cdot 8 \%$ and $2 \cdot 3 \%$, respectively). Individual $\mathrm{BMD}$ values were expressed as SD units ( $Z$-values) in relation to reference population of our Centre. ${ }^{20}$ Conventional spinal radiograph in lateral (T4-L4) and antero-posterior (AP) projection (L1-L4) were obtained in all subjects with standardized technique. Two trained radiologists, who were blinded to BMD and hormonal data, independently reviewed the radiographs. Vertebral fractures were diagnosed on visual inspection using the semiquantitative visual assessment (SQ), previously described by Genant et al. ${ }^{21}$ According to this technique, fractures assessed on lateral thoracolumbar spine radiographs were defined as reductions of more than $20 \%$ in anterior, middle or posterior vertebral height. From lateral spine radiographs, each vertebra is visually assessed as intact (SQ Grade 0) or as having approximately mild (20-25\% compression), moderate (25-40\% compression), or severe ( $>40 \%$ compression) deformity (SQ Grades 1, 2 and 3, respectively). The radiologists discussed questionable cases to agree on a diagnosis; the interrate reliability between the two radiologists was good $(\kappa=0 \cdot 86)$.

\section{Statistical analysis}

Statistical analysis was performed by spss version $12 \cdot 0$ statistical package (SPSS Inc., Chicago, IL). The results are expressed as mean \pm SD.

Comparison of continuous variables among the different groups was performed using one-way ANOVA and Bonferroni posthoc analysis. Categorical variables were compared by $\chi^{2}$ test. The associations between indexes of cortisol secretion and bone mass were tested by either Pearson Product Moment or Spearman correlation as appropriate.

In all patients multivariate linear regression analysis was used to evaluate the influence of $\mathrm{SH}$ on BMD after adjusting for body mass index (BMI), testosterone, DHEA-S levels. 
In all patients, logistic regression analysis assessed the association between the presence of fractures (dependent variables, expressed as categorical variable) and independent variables: age, BMI, DHEA-S, testosterone, presence of $\mathrm{SH}$ and spinal BMD (expressed as $Z$-score).

$P$-values of $<0.05$ were considered significant.

\section{Results}

Clinical characteristics of patients with and without $\mathrm{SH}$ and controls are reported in Table 1. Patients with $\mathrm{SH}$, without $\mathrm{SH}$ and controls were comparable for age, BMI and testosterone levels (Table 1). As expected, cortisol after Dex and UFC levels were higher, while ACTH and DHEA-S levels lower in $\mathrm{SH}+$ than in $\mathrm{SH}$-patients (Table 1). The proportion of patients with hypertension and type 2 diabetes was higher in $\mathrm{SH}+$ than in $\mathrm{SH}-$ patients (Table 1).
Patients with $\mathrm{SH}$ had lower BMD at lumbar spine (LS) and FN as compared to those without $\mathrm{SH}$ and controls (Table 1). The proportion of patients with osteoporosis (defined on the basis of the presence of BMD $T$-score $\leq-2 \cdot 5$ and/or vertebral fractures) and with vertebral fractures (Table 1 and Fig. 1) was higher in $\mathrm{SH}+$ patients than in SH- and control subjects. All vertebral fractures were asymptomatic. The $40.9 \%$ of fractured patients with SH had a BMD measured at any site that, according to the World Health Organization densitometric criteria, ${ }^{22}$ was normal or 'osteopenic' (BMD T-score $>-2 \cdot 5)$; this proportion was higher in $\mathrm{SH}+$ as compared to $\mathrm{SH}-$ $(18 \cdot 2 \%, P=0 \cdot 047)$ and control subjects $(15 \cdot 6 \%, P=0 \cdot 016)$ (Table 1 and Fig. 2).

Bivariate correlation analysis showed that there is an overall negative correlation between LS BMD and UFC levels $(R=-0 \cdot 30$, $P=0 \cdot 005)$. Multivariate linear regression analyses showed that LS BMD was inversely associated to UFC levels and also to the presence

Table 1. Clinical characteristics of patients and controls

\begin{tabular}{|c|c|c|c|}
\hline & $\begin{array}{l}\text { Control subjects } \\
(n=90)\end{array}$ & $\begin{array}{l}\text { SH- patients } \\
(n=66)\end{array}$ & $\begin{array}{l}\text { SH+ patients } \\
(n=22)\end{array}$ \\
\hline Age (years) & $\begin{array}{l}61 \cdot 8 \pm 14 \cdot 2 \\
(23 \cdot 0-90 \cdot 0)\end{array}$ & $\begin{array}{l}60 \cdot 9 \pm 12 \cdot 9 \\
(21 \cdot 0-83 \cdot 0)\end{array}$ & $\begin{array}{l}65 \cdot 8 \pm 10 \cdot 7 \\
(42 \cdot 0-86 \cdot 0)\end{array}$ \\
\hline BMI $\left(\mathrm{kg} / \mathrm{m}^{2}\right)$ & $\begin{array}{l}27 \cdot 7 \pm 3 \cdot 2 \\
(21 \cdot 4-36 \cdot 7)\end{array}$ & $\begin{array}{l}28 \cdot 1 \pm 3 \cdot 1 \\
(22 \cdot 9-38 \cdot 1)\end{array}$ & $\begin{array}{l}28 \cdot 5 \pm 3 \cdot 2 \\
(24 \cdot 6-37 \cdot 1)\end{array}$ \\
\hline Testosterone (nmol/l) & $\begin{array}{l}17 \cdot 5 \pm 5 \cdot 6 \\
(10 \cdot 9-30 \cdot 8)\end{array}$ & $\begin{array}{l}17 \cdot 9 \pm 6 \cdot 3 \\
(10 \cdot 5-35 \cdot 4)\end{array}$ & $\begin{array}{l}16 \cdot 1 \pm 5 \cdot 3 \\
(10 \cdot 5-31 \cdot 2)\end{array}$ \\
\hline Urinary free cortisol (nmol/24 h) & - & $\begin{array}{l}133 \cdot 6 \pm 61 \cdot 3 \\
(41 \cdot 4-327 \cdot 1)\end{array}$ & $\begin{array}{l}201 \cdot 2 \pm 83 \cdot 6^{*} \\
(64 \cdot 3-438 \cdot 8)\end{array}$ \\
\hline Cortisol after Dex (nmol/l) & - & $\begin{array}{l}46 \cdot 9 \pm 24 \cdot 8 \\
(13 \cdot 8-173 \cdot 9)\end{array}$ & $\begin{array}{l}124 \cdot 2 \pm 77 \cdot 3^{*} \\
(38 \cdot 6-358 \cdot 8)\end{array}$ \\
\hline ACTH (pmol/l) & - & $\begin{array}{l}4 \cdot 1 \pm 0 \cdot 3 \\
(0 \cdot 24-3 \cdot 2)\end{array}$ & $\begin{array}{l}1 \cdot 7 \pm 0 \cdot 8^{*} \\
(0 \cdot 5-3 \cdot 6)\end{array}$ \\
\hline DHEA-S $(\mu \mathrm{mol} / \mathrm{l})$ & - & $\begin{array}{l}2 \cdot 6 \pm 2 \cdot 2 \\
(0 \cdot 4-10 \cdot 0)\end{array}$ & $\begin{array}{l}1 \cdot 4 \pm 1 \cdot 0 \dagger \\
(0 \cdot 4-4 \cdot 0)\end{array}$ \\
\hline Lumbar spine BMD ( $Z$-score) & $\begin{array}{l}0 \cdot 20 \pm 1 \cdot 28 \\
(-2 \cdot 30-2 \cdot 90)\end{array}$ & $\begin{array}{l}0 \cdot 19 \pm 1 \cdot 34 \\
(-2 \cdot 80-3 \cdot 60)\end{array}$ & $\begin{array}{l}-1 \cdot 04 \pm 1 \cdot 84 \ddagger \\
(-4 \cdot 50-4 \cdot 10)\end{array}$ \\
\hline Femoral neck BMD ( $Z$-score $)$ & $\begin{array}{l}0 \cdot 26 \pm 1 \cdot 06 \\
(-2 \cdot 30-2 \cdot 90)\end{array}$ & $\begin{array}{l}0 \cdot 01 \pm 1 \cdot 01 \\
(-2 \cdot 8-2 \cdot 1)\end{array}$ & $\begin{array}{l}-0 \cdot 63 \pm 1 \cdot 01 \S 9 \\
(-2 \cdot 5-1 \cdot 5)\end{array}$ \\
\hline Subjects with osteoporosis§§ (\%) & $\begin{array}{l}15 \\
(16 \cdot 7)\end{array}$ & $\begin{array}{l}12 \\
(18 \cdot 2)\end{array}$ & $\begin{array}{l}9 \$ \dagger \dagger \\
(40 \cdot 9)\end{array}$ \\
\hline Subjects with vertebral fractures (\%) & $\begin{array}{l}18 \\
(20 \cdot 0)\end{array}$ & $\begin{array}{l}14 \\
(21 \cdot 2)\end{array}$ & $\begin{array}{l}16 \neq \\
(72 \cdot 7)\end{array}$ \\
\hline Subjects with vertebral fractures and BMD $T$-score $>-2.5$ & $\begin{array}{l}14 \\
(15 \cdot 6)\end{array}$ & $\begin{array}{l}12 \\
(18 \cdot 2)\end{array}$ & $\begin{array}{l}9 \S \neq \neq \\
(40 \cdot 9)\end{array}$ \\
\hline Subjects with hypertension (\%) & $\begin{array}{l}43 \\
(47 \cdot 8)\end{array}$ & $\begin{array}{l}28 \\
(42 \cdot 4)\end{array}$ & $\begin{array}{l}16^{\star *} \\
(72 \cdot 7)\end{array}$ \\
\hline Subjects with type 2 diabetes (\%) & $\begin{array}{l}19 \\
(21 \cdot 1)\end{array}$ & $\begin{array}{l}13 \\
(19 \cdot 7)\end{array}$ & $\begin{array}{l}10^{\star *} \\
(45 \cdot 5)\end{array}$ \\
\hline
\end{tabular}

Data are expressed as mean $\pm \mathrm{SD}$ with range in parenthesis or, absolute number with percentage in parenthesis.

${ }^{\star} P=0.001$ vs. SH-patients, $P=0.016$ vs. SH-patients, $\ddagger P=0.001$ vs. $\mathrm{SH}$ - patients and control subjects, $\$ P=0 \cdot 047$ vs. SH- patients, $9 P=0 \cdot 001 v s$. control subjects, ${ }^{\star *} P=0.025$ vs. SH- patients, $\dagger \dagger P=0.032$ vs. control subjects, $\ddagger \ddagger P=0.016$ vs. control subjects.

Cortisol after Dex, serum cortisol after 1-mg dexamethasone suppression test; BMD, bone mineral density measured by dual X-ray absorptiometry; $\mathrm{SH}$, subclinical hypercortisolism was diagnosed in presence of two out of the following: cortisol after Dex $>82 \cdot 7 \mathrm{nmol} / \mathrm{l}$, urinary free cortisol levels $>193 \cdot 0 \mathrm{nmol} /$ 24h, serum ACTH levels $<2 \cdot 2 \mathrm{pmol} / \mathrm{l}$.

$\$ \$$ Osteoporosis: BMD $T$-score less than $-2 \cdot 5$ at any measured site and/or vertebral fractures. 


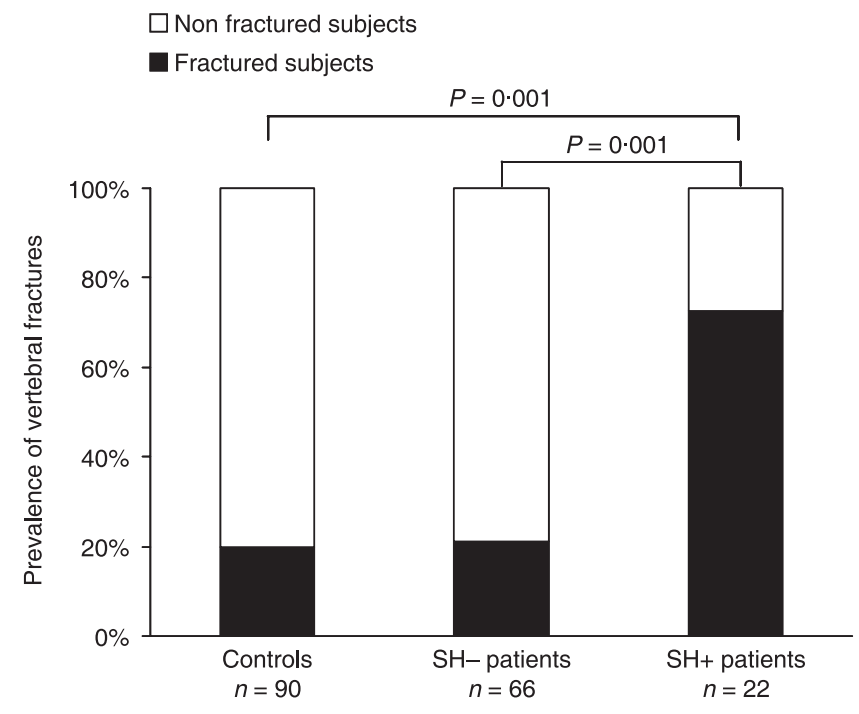

Fig. 1 Prevalence of vertebral fractures in eugonadal male patients with adrenal incidentalomas in relation to the presence of subclinical hypercortisolism.

Table 2. Odds ratio for detecting vertebral fracture for potential risk factors using multivariable logistic regression model

\begin{tabular}{llll}
\hline & Odds ratio & $P$ value & $95 \%$ CI \\
\hline Age (10 year increase) & $2 \cdot 20$ & $0 \cdot 009$ & $1 \cdot 21-3 \cdot 97$ \\
BMI (1 SD increase) & $0 \cdot 57$ & $0 \cdot 155$ & $0 \cdot 70-3 \cdot 84$ \\
DHEA-S (1 SD increase) & 0.97 & $0 \cdot 960$ & $0 \cdot 33-3 \cdot 33$ \\
Testosterone (1 SD increase) & $0 \cdot 92$ & $0 \cdot 841$ & $0 \cdot 47-0 \cdot 56$ \\
SH (presence $v s$. absence) & $7 \cdot 24$ & $0 \cdot 002$ & $2 \cdot 13-24 \cdot 60$ \\
Lumbar spine BMD (1 SD increase) & $0 \cdot 41$ & $0 \cdot 050$ & $1 \cdot 01-5 \cdot 88$ \\
\hline
\end{tabular}

SD, standard deviation; BMI, body mass index; DHEA-S,

dehydroepiandrosterone levels; $\mathrm{SH}$, subclinical hypercortisolism was diagnosed in presence of two out of the following: cortisol levels after 1-mg dexamethasone suppression test higher than $82 \cdot 8 \mathrm{nmol} / \mathrm{l}$, urinary free cortisol levels higher than $193.0 \mathrm{nmol} / 24 \mathrm{~h}$, serum ACTH levels lower than $2 \cdot 2 \mathrm{pmol} / \mathrm{l}$.

The logistic regression analysis assessed the association between the presence of fractures (dependent variables, expressed as categorical variable) and independent variables: age, BMI, DHEA-S, testosterone, presence of SH and spinal BMD (expressed as $Z$-score).

of SH ( $\beta=-0 \cdot 338, P=0.02$ and $\beta=-0 \cdot 378, P=0 \cdot 0001$, respectively) after adjustment for age, BMI, testosterone and DHEA-S levels.

The presence of vertebral fractures was significantly associated to the presence of SH also when age, BMI, DHEA-S, testosterone levels and LS BMD were added to the model as shown by logistic regression analysis (Table 2).

\section{Discussion}

Our study confirms that in male patients with $\mathrm{AI}$ and $\mathrm{SH}$ bone mass is reduced and demonstrates that in these patients the proportion of vertebral fractures is increased. BMD and the presence of fractures

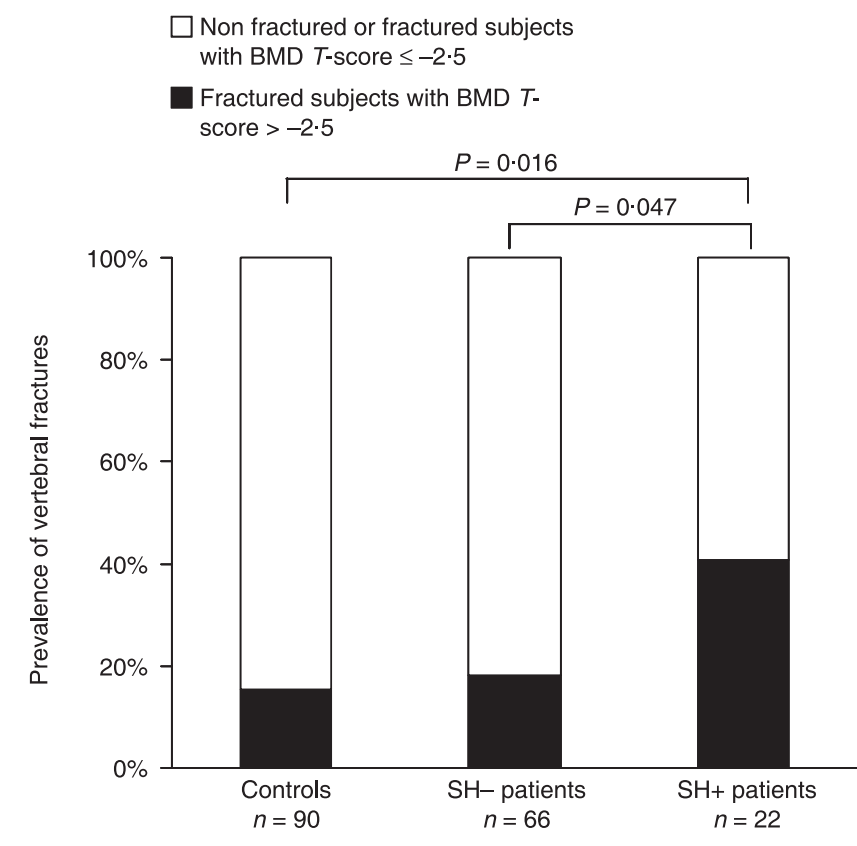

Fig. 2 Prevalence of vertebral fractures in eugonadal male patients with adrenal incidentalomas and normal or 'osteopenic' bone mineral density in patients with and without subclinical hypercortisolism.

are related to the degree of cortisol secretion. This negative effect of $\mathrm{SH}$ on bone is present despite the eugonadal status of patients.

In the recent years, the term 'subclinical hypercortisolism' has been used to define a condition of subtle hypercortisolism characterized by altered biochemical parameters of HPA axis in the absence of the classical signs or symptoms of overt cortisol excess. ${ }^{3}$ This condition has been described in up to $20 \%$ of patients bearing an $\mathrm{AI}^{2}$ In fact, in spite of the definition of 'subclinical' hypercortisolism, this condition of subtle cortisol excess has been described to be associated with the presence of classic, even not specific, complications of overt cortisol excess as obesity, type 2 diabetes, hypertension and bone loss. ${ }^{4-12,23-25}$

Regarding bone involvement in the presence of $\mathrm{SH}$, no data are reported so far regarding vertebral fractures in male patients. Thus, the most important finding of the present investigation is that in male patients with $\mathrm{AI}$ and $\mathrm{SH}$ the proportion of vertebral fractures is increased. Furthermore, the negative effect of $\mathrm{SH}$ on bone is present in spite of the eugonadal status of patients. This is in keeping with previous data showing a reduced BMD in eugonadal male patients with $\mathrm{AI}$ and $\mathrm{SH},{ }^{9}$ and with previous findings in eugonadal female patients with subclinical ${ }^{8,12}$ and overt cortisol excess. ${ }^{26,27}$ However, the prevalence of vertebral fractures found in this study in eugonadal male patients $(72.7 \%)$ is somewhat higher as compared to that found in eugonadal female subjects (42.9\%) in an our previous study. ${ }^{12}$ In our opinion this discrepancy could be due to the different mean age of the two samples (66 and 43 years, respectively) and therefore to the possible difference in the disease duration.

Interestingly, in our patients the presence of vertebral fractures is associated with the presence of $\mathrm{SH}$ regardless of age, BMI, testosterone and DHEA-S levels, and of utmost importance, bone mass. 
Moreover, in all subjects vertebral fractures were asymptomatic and the $40 \%$ of fractured patients with SH had a BMD measured at any site that, according to the World Health Organization densitometric criteria, ${ }^{22}$ was normal or 'osteopenic' (BMD T-score $>-2 \cdot 5$ ). As vertebral fractures are strong predictors of future fracture risk, ${ }^{16}$ these findings suggest that in patients with $\mathrm{AI}$ and $\mathrm{SH}$ conventional spinal radiograph is mandatory even in the absence of hypogonadism, back pain or reduced BMD. In addition, the proportion of subjects with BMD $T$-score $>-2 \cdot 5$, but with vertebral fractures, was higher in $\mathrm{SH}+$ than in $\mathrm{SH}-$ patients and in controls (Fig. 2). This finding suggests that, similarly to what is reported in the presence of overt cortisol excess, also in $\mathrm{SH}$ the risk of fractures is increased for a given T-score. ${ }^{4}$ This may be due to the fact that cortisol excess affects not only bone mass but also bone quality. ${ }^{4}$

Finally, patients with $\mathrm{SH}$ showed a higher prevalence of hypertension and diabetes as compared to patients without $\mathrm{SH}$. These findings confirm the observations from several previous studies, ${ }^{23-25}$ and reinforce the idea that the condition of subtle cortisol excess, even if 'subclinical', may cause the same consequences of overt cortisol excess. However, the cross-sectional design of our study allows us to show association but not causality. Nevertheless, given the well recognized negative effect of cortisol excess on bone, a causative role of $\mathrm{SH}$ on reduction of bone mass and increase of fractures is likely. In addition, a tight link between $\mathrm{SH}$ and low bone mass and fractures has been recently confirmed by a study reporting a high prevalence of $\mathrm{SH}$ in patients with established osteoporosis. ${ }^{28}$

In summary, although caution is needed considering the low statistical power of the study, our data seem to indicate that in eugonadal male patients with adrenal incidentalomas subclinical hypercortisolism is associated with low bone mass and high proportion of vertebral fractures and bone mass and presence of vertebral fractures are related to the degree of cortisol secretion. Prospective longitudinal intervention studies are needed to confirm the causative role of $\mathrm{SH}$ on bone loss and risk of fractures.

\section{Acknowledgements}

We acknowledge Prof Vincenzo Trischitta, for the deep review of the manuscript.

\section{References}

1 Kloos, R.T., Gross, M.D., Francis, I.R. et al. (1995) Incidentally discovered adrenal masses. Endocrine Reviews, 16, 460-484.

2 Terzolo, M., Osella, G., Alì, A. et al. (1998) Subclinical Cushing's syndrome in adrenal incidentalomas. Clinical Endocrinology, 48, 89-97.

3 Reincke, M. (2000) Subclinical Cushing's Syndrome. Endocrinology Metabolism Clinics of North America, 29, 47-56.

4 Mazziotti, G., Angeli, A., Bilezikian, J.P. et al. (2006) Glucocorticoidinduced osteoporosis: an update. Trends in Endocrinology and Metabolism, 17, 144-149.

5 Chiodini, I., Battista, C., Carnevale, V. et al. (2007) Skeletal involvement in adults patients with endogenous hypercortisolism. Journal of Endocrinological Investigation, 31, 267-276.

6 Tauchmanovà, L., Rossi, R., Nuzzo, V. et al. (2001) Bone loss determined by quantitative ultrasonometry correlates inversely with disease activity in patients with endogenous glucocorticoid excess due to adrenal mass. European Journal of Endocrinology, 145, 241-247.

7 Torlontano, M., Chiodini, I., Pileri Guglielmi, G. et al. (1999) Altered bone mass and turnover in female patients with adrenal incidentaloma: the effect of subclinical hypercortisolism. Journal of Clinical Endocrinology and Metabolism, 84, 2381-2385.

8 Chiodini, I., Torlontano, M., Carnevale, V. et al. (2001) Bone loss rate in adrenal incidentalomas: a longitudinal study. Journal of Clinical Endocrinology and Metabolism, 86, 5337-5341.

9 Chiodini, I., Tauchmanovà, L., Torlontano, M. et al. (2002) Bone involvement in eugonadal male patients with adrenal incidentaloma and subclinical hypercortisolism. Journal of Clinical Endocrinology and Metabolism, 87, 5491-5494.

10 Bardet, S., Rohmer, V., Boux de Casson, F. et al. (2002) Bone density and biochemical bone markers in patients with adrenal incidentalomas: effect of subclinical hypercortisolism. La Revue de Médicine Interne, 23, 508-517.

11 Hadjidakis, D., Tsagarakis, S. \& Roboti, C. (2003) Does subclinical hypercortisolism adversely affect the bone mineral density of patients with adrenal incidentalomas? Clinical Endocrinology, 58, $72-77$.

12 Chiodini, I., Guglielmi, G., Battista, C. et al. (2004) Spinal volume tric bone mineral density and vertebral fractures in female patients with adrenal incidentalomas: the effect of subclinical hypercortisolism and gonadal status. Journal of Clinical Endocrinology and Metabolism, 89, 2237-2241.

13 Francucci, C.M., Pantanetti, P., Garrapa, G.G. et al. (2002) Bone metabolism and mass in women with Cushing's syndrome and adrenal incidentaloma. Clinical Endocrinology, 57, 587-593.

14 Rossi, R., Tauchmanovà, L., Luciano, A. et al. (2000) Subclinical Cushing's syndrome in patients with adrenal incidentaloma: clinical and biochemical features. Journal of Clinical Endocrinology and Metabolism, 85, 1440-1448.

15 Osella, G., Reimondo, G., Peretti, P. et al. (2001) The patients with incidentally discovered adrenal adenoma (incidentaloma) are not at increased risk of osteoporosis. Journal of Clinical Endocrinology and Metabolism, 86, 604-607.

16 Delmas, P.D., Genant, H.K., Crans, G.G. et al. (2003) Severity of prevalent vertebral fractures and the risk of subsequent vertebral and non-vertebral fractures: results for the MORE trial. Bone, 33, 522532.

17 Reid, I.R., France, J.T., Pybus, J. et al. (1985) Plasma testosterone concentrations in asthmatic men treated with glucocorticoids. British Medical Journal, 291, 574.

18 Bhasin, S., Cunningham, G.R., Hayes, F.J. et al. (2006) Testosterone therapy in adult men with androgen deficiency syndromes: an endocrine society clinical practical guideline. Journal of Clinical Endocrinology and Metabolism, 9, 1995-2010.

19 Kratz, A., Ferraro, M., Sluss, P.M. et al. (2004) Laboratory reference values. New England Journal of Medicine, 351, 1548-1563.

20 Guglielmi, G., Giannatempo, G.M., Blunt, B.A. et al. (1995) Spinal bone mineral density by quantitative $\mathrm{CT}$ in a normal Italian population. European Radiology, 5, 269-275.

21 Genant, H.K., Wu, C.Y., van Knijk, C. et al. (1993) Vertebral fracture assessment using a semi-quantitative technique. Journal of Bone Mineral Research, 8, 1137-1148.

22 Kanis, J.A. (2002) Diagnosis of osteoporosis and assessment of fracture risk. Lancet, 359, 1929-1936.

23 Terzolo, M., Pia, A., Alì, A. et al. (2002) Adrenal incidentaloma: a new cause of the metabolic syndrome? Journal of Clinical Endocrinology and Metabolism, 87, 998-1003. 
24 Tauchmanovà, L., Rossi, R., Biondi, B. et al. (2002) Patients with subclinical Cushing's syndrome due to adrenal adenoma have increased cardiovascular risk. Journal of Clinical Endocrinology and Metabolism, 87, 4872-4878.

25 Bernini, G., Moretti, A., Iacconi, P. et al. (2003) Anthropometric, haemodynamic, humoral and hormonal evaluation in patients with incidental adrenocortical adenomas before and after surgery. European Journal of Endocrinology, 148, 213-219.

26 Chiodini, I., Carnevale, V., Torlontano, M. et al. (1998) Alterations of bone turnover and mass at different skeletal sites due to pure glucocorticoid excess: study in eumenorrheic patients with Cushing's syndrome. Journal of Clinical Endocrinology and Metabolism, 83, 1863-1867.

27 Tauchmanovà, L., Pivonello, R., Di Somma, C. et al. (2006) Bone demineralization and vertebral fractures in endogenous cortisol excess: role of disease etiology and gonadal status. Journal of Clinical Endocrinology and Metabolism, 83, 1779-1784.

28 Chiodini, I., Mascia, M.L., Muscarella, S. et al. (2007) Subclinical hypercortisolism among outpatients referred for 'Osteoporosis'. Annals of Internal Medicine, 147, 541-548. 